\section{Trends in upper gastrointestinal bleeding during the COVID-19 pandemic}

\section{Zain A. Sobani, Swathi Paleti, Sameen Khalid, Euriko Torrazza Perez, Tarun Rustagi}

University of New Mexico, NM, USA

The COVID-19 pandemic has significantly impacted the entire world, including the United States and specifically its healthcare system. Based on recommendations from all major Gastrointestinal Societies [1], we postponed all non-urgent procedures at our institution with effect from March 16th, 2020. After postponing non-emergent procedures, we aimed to evaluate the trends of upper gastrointestinal (GI) bleeding and esophagogastroduodenoscopy (EGD) performed during the COVID-19 pandemic. We conducted a retrospective review of all patients undergoing EGDs at our institution during the study period (March 16 to April 15, 2020). In addition, we collected similar data from the preceding 2 months (January 1 to February 29, 2020) and the same time period from the preceding year (March 16 to April 15, 2019) for comparison, to account for any seasonal variation.

Prior to COVID-19, we performed an average of $398 \pm 38.3$ EGDs per month, of which $23.5 \%(93.67 \pm 13.58)$ were performed on an inpatient basis. With an overall reduction in inpatient procedures of about $49.82 \%$, the proportion of patients undergoing inpatient EGD for GI bleeding was comparatively higher ( $78.7 \%$ vs. $65.1 \% ; \mathrm{P}=0.0925)$, as well as the proportion of EGDs for GI bleeding performed in the intensive care unit (ICU) (51.4\% vs. $33.3 \%$; $\mathrm{P}=0.0415)$ (Table 1$)$. There was no change in the proportion of patients with GI bleeding requiring endoscopic intervention during this time period ( $32.4 \%$ vs. $32.2 \% ; \mathrm{P}=1$ ). Despite a shift in the proportion of patients, there was no trend noted in the absolute number of inpatients with hemodynamically unstable GI bleeding, EGDs performed in the ICU or the number of inpatients undergoing EGD for variceal bleeding (Table 1).

When preparing for the COVID-19 pandemic, we expected the same baseline prevalence of emergent conditions, including acute exacerbations of chronic disease, acute infections, GI emergencies, cerebrovascular and coronary events, with the addition of the patients presenting with COVID-19. This was however refuted by studies on other acute emergencies such as myocardial infarction $[2,3]$.

However, we found no change in the absolute number of patients with hemodynamically unstable GI bleeding, the number of EGDs performed in the ICU or the number of EGDs performed for variceal bleeding. This may in part be attributed to the more vivid presentation of overt GI bleeding, making it hard to ignore. There was, however, a significant reduction in the number of EGDs done on an inpatient basis, indicating fewer overall inpatient admissions and more stringent triage criteria for endoscopy during this COVID-19 study period. The increased proportions can be explained by a reduction in the number of non-urgent procedures.

It is imperative for gastroenterologists to be aware that GI symptoms were noted to be among the repertoire of COVID-19, especially in patients with severe disease and in the later stages of the pandemic. Further data suggest that GI bleeding was present in about 4-13.7\% patients with COVID-19 [4]. Based on our data, and given that our region still has not reached its expected peak of COVID-19, we expect to see an increase

Table 1 EGD volume and indications during the study period compared to prior months

\begin{tabular}{|c|c|c|c|c|}
\hline Characteristics & $1 / 1 / 2020-1 / 31 / 2020$ & $2 / 1 / 2020-2 / 29 / 20202$ & $3 / 16 / 2020-4 / 15 / 2020$ & $3 / 16 / 2019-4 / 15 / 2019$ \\
\hline Total EGD volume & 424 & 354 & 140 & 416 \\
\hline Inpatient & 108 & 81 & 47 & 92 \\
\hline Outpatient & 316 & 273 & 93 & 324 \\
\hline \multicolumn{5}{|l|}{ Characteristics of inpatient EGDs } \\
\hline Age & $54.6 \pm 17.6$ & $53.7 \pm 15$ & $53.8 \pm 15.8$ & $57.8 \pm 14.8$ \\
\hline Sex (female \%) & 42.6 & 42 & 44.7 & 41.3 \\
\hline \multicolumn{5}{|l|}{ Indications } \\
\hline Non-bleeding & 33 & 27 & 10 & 38 \\
\hline Bleeding & 75 & 54 & 37 & 54 \\
\hline HD unstable & 17 & 14 & 11 & 28 \\
\hline Variceal & 13 & 11 & 9 & 7 \\
\hline Non-variceal & 62 & 43 & 28 & 47 \\
\hline \multicolumn{5}{|l|}{ Location } \\
\hline Endoscopy unit & 83 & 68 & 28 & 69 \\
\hline ICU, reason for ICU admission & 25 & 13 & 19 & 23 \\
\hline GI bleed & 18 & 8 & 13 & 18 \\
\hline Variceal GIB & 6 & 3 & 6 & 2 \\
\hline Non-GIB-related admission & 7 & 5 & 6 & 5 \\
\hline Endoscopic therapy for GIB & 20 & 16 & 12 & 23 \\
\hline
\end{tabular}

EGD, esophagogastroduodenoscopy; HD, hemodynamically; ICU, intensive care unit; GI, gastrointestinal; GIB, gastrointestinal bleeding 
in the number of patients with hemodynamically unstable bleeding with the surge of COVID-19.

\section{References}

1. Bezerra JA, El-Serag HB, Pochapin MB, Vargo JJ. COVID-19 clinical insights for our community of gastroenterologists and gastroenterology care providers. Available from: https:// gi.org/2020/03/15/joint-gi-society-message-on-covid-19/ [Accessed 15 June 2020].

2. Garcia S, Albaghdadi MS, Meraj PM, et al. Reduction in STsegment elevation cardiac catheterization laboratory activations in the United States during COVID-19 pandemic. J Am Coll Cardiol 2020;75:2871-2872.

3. Rodríguez-Leor O, Alvarez-Álvarez B, Ojeda S, et al. Impacto de la pandemia de COVID-19 sobre la actividad asistencial en cardiología intervencionista en España. REC Interv Cardiol
2020;2:82-89.

4. Tian Y, Rong L, Nian W, He Y. Review article: gastrointestinal features in COVID-19 and the possibility of faecal transmission. Aliment Pharmacol Ther 2020;51:843-851.

Division of Gastroenterology and Hepatology, Department of Internal Medicine, University of New Mexico, NM, USA

Conflict of Interest: None

Correspondence to: Tarun Rustagi, MD, Division of Gastroenterology and Hepatology, Department of Internal Medicine, University of New Mexico, MSC10 5550, 1 University of New Mexico, Albuquerque NM 87131, USA, e-mail: tarunrustagi06@gmail.com

Received 8 May 2020; accepted 14 May 2020;

published online 30 June 2020

DOI: https://doi.org/10.20524/aog.2020.0510 